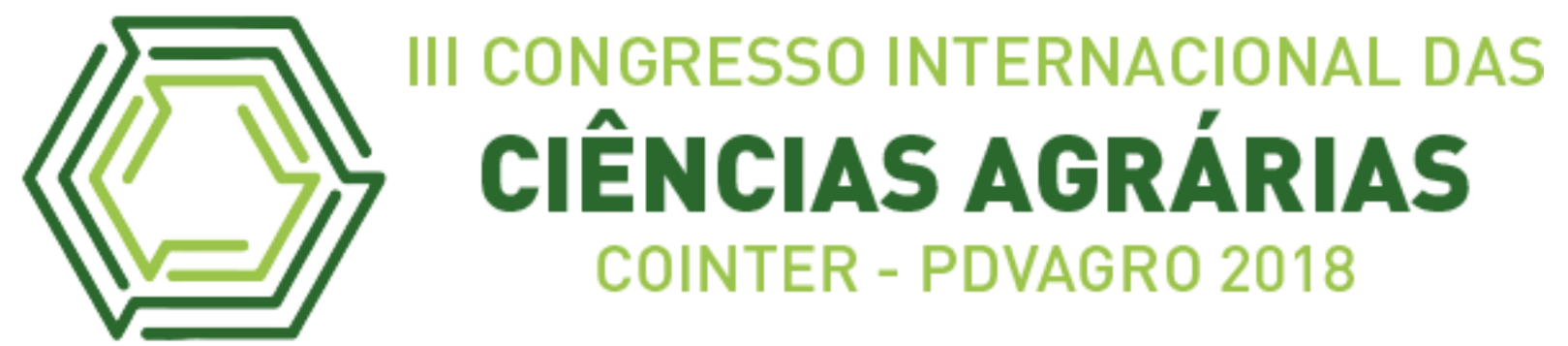

\title{
ESPECTRO DE GOTAS DA PONTA DE PULVERIZAÇÃO TT-11001 SOB DIFERENTES PRESSÕES
}

\section{SPECTRO OF DROPS OF THE PULVERIZATION TT-11001 UNDER DIFFERENT PRESSURES}

\author{
Apresentação: Pôster
}

\begin{abstract}
Pedro Luid de Sousa Oliveira ${ }^{1}$; Roxana Stefane Mendes Nascimento ${ }^{2}$; Jossimara Ferreira Damascena ${ }^{3}$; Wellington Luiz de Oliveira ${ }^{4}$; Douglas Ferreira Parreira ${ }^{5}$.
\end{abstract}

DOI: https://doi.org/10.31692/2526-7701.IIICOINTERPDVAGRO.2018.00469

\section{INTRODUÇÃO}

A aplicação eficiente de produtos fitossanitários se faz necessária para obtenção de bom controle de pragas, doenças e plantas daninhas, sendo assim, devem ser observados vários fatores, dentre eles, o tipo de produto, volume de calda, tipo de pulverizador e espectro de gotas produzidas pelas pontas de pulverização, horário de aplicação, condições ambientais. No que se refere às pontas de pulverização, a variação no tamanho de gotas produzidas recebe o nome de espectro.

No momento da pulverização, maior eficiência no controle pode ser obtida a partir de um espectro de gotas mais homogêneo, ou seja, não devem ser produzidas gotas muito finas nem muito grossas, dessa forma, reduzem-se perdas por deriva e escorrimento superficial, consequentemente, as aplicações se tornam mais eficientes e seguras do ponto de vista ambiental (CUNHA et al., 2010).

As pontas de pulverização são responsáveis pela determinação da vazão da calda, pela distribuição uniforme do produto fitossanitário sobre o alvo biológico e pela formação das gotas de tamanho compatível com a finalidade a que se destinam, por isso tornam-se os componentes mais importantes de um pulverizador (MATTHEWS, 1979).

\footnotetext{
${ }^{1}$ Doutoranda em Fitotecnia, Universidade Federal de Viçosa - UFV, roxana.mendes@ hotmail.com

${ }^{2}$ Estudante do curso de Eng. Agronômica, Universidade Estadual da Região Tocantina do Maranhão UEMASUL, pluid93@ hotmail.com

${ }^{3}$ Estudante do curso de Eng. Agronômica, Universidade Estadual da Região Tocantina do Maranhão UEMASUL,

${ }^{4}$ Estudante do curso de Eng. Agronômica, Universidade Federal de Viçosa - UFV

${ }^{5}$ Pós-doutorando; Universidade Federal de Viçosa - UFV,
} 
O tamanho das gotas está diretamente ligado à pressão de trabalho dos pulverizadores, pois quanto maior a pressão menor o tamanho das gotas. Recomenda-se trabalhar dentro de pressão adequada, pois ela também interfere no ângulo de pulverização e na cobertura, a pressão adequada pode ser encontrada nos catálogos de pontas de pulverização (CAMARA et al., 2008; TEEJET TECHNOLOGIES, 2013)

Desse modo, objetivou-se com o presente trabalho avaliar o espectro de gotas da ponta TT-11001submetida a diferentes pressões.

\section{FUNDAMENTAÇÃO TEÓRICA}

Uma correta tecnologia de aplicação de agrotóxicos com máxima eficiência e de maneira mais econômica possível, reduzindo impactos ao meio ambiente visa colocar a quantidade certa de ingrediente ativo no alvo (MATTHEWS, 2002). Dentre as técnicas de aplicação de agrotóxicos, as que se baseiam na pulverização hidráulica são as mais difundidas por apresentares flexibilidade a diferentes situações (TEIXEIRA, 1997).

As pontas de pulverização promovem características que asseguram melhor segurança e efetividade no controle de pragas, doenças e plantas daninhas, por isso são consideradas os principais componentes das pontas de pulverização. $\mathrm{O}$ sucesso na aplicação de agrotóxico acontece quando se dispõe de pontas de pulverização que propiciem distribuição transversal uniforme, espectro de gotas semelhante e de tamanho adequado (CUNHA, 2003).

Para a aplicação de defensivos agrícolas é muito importante a determinação do espectro de gotas produzidas pelas pontas de pulverização. A partir dessa informação, efetuase a escolha da ponta de acordo com o potencial de deriva, as características do herbicida e os riscos de volatilização e escorrimento de calda nas folhas das plantas daninhas. Vazão nominal, ângulo de descarga, pressão de operação, propriedades da calda e tipo de ponta de pulverização são os fatores que influenciam o espectro de gotas produzidas por determinada ponta de pulverização são: (CUNHA et al., 2007).

A distribuição uniforme da calda aplicada em um alvo utilizando-se pulverizadores de agroquímicos é dada pelas condições de montagem e de como o equipamento é operacionalizado, como o espaçamento entre os bicos, a altura da barra, o ângulo de abertura dos jatos e a pressão hidráulica de trabalho (PERECIN et al, 1998). 


\section{METODOLOGIA}

O experimento foi conduzido no Laboratório de Mecanização Agrícola, pertencente ao Departamento de Engenharia Agrícola da Universidade Federal de Viçosa (DEA/UFV), Viçosa, Minas Gerais. Foi avaliada a ponta de jato plano defletor (TT-11001) nas pressões de trabalho de $300 \mathrm{KPa}$ (3 Bar), $400 \mathrm{KPa}$ (4 Bar) e $500 \mathrm{KPa}$ (5 Bar). A ponta TT110 01 é uma ponta de jato plano defletor sendo que o espectro de gotas produzido é classificado entre fino e grosso. Altura recomendada $0,50 \mathrm{~m}$, pressão 100 a $600 \mathrm{kPa}$ (1 a 6 bar), espaçamento entre pontas de $0,50 \mathrm{~m}$ e ângulo de aspersão de $110^{\circ}$.

A análise do espectro de gotas das pontas hidráulicas foi realizada de forma direta com um analisador de partículas em tempo real (Spraytec, Malvern Instruments Ltd). Este equipamento dispõe de unidade óptica, constituída por uma lente focal de $750 \mathrm{~mm}$ e foi calibrado para mensurar gotas na classe de tamanho de 0,10 a $2.500 \mu \mathrm{m}$.

As pontas foram instaladas em uma barra de pulverização, composta por um bico e um manômetro, montada sobre o analisador, a 0,50 m de distância do feixe de laser, e, ao final dessa barra, foi instalado um motor elétrico para permitir que a barra se movimentasse $55^{\circ}$ para a direita e para a esquerda, com o intuito de que todo o jato atravessasse transversalmente o feixe luminoso emitido pelo laser durante a leitura. As análises foram realizadas somente em temperaturas inferiores a $25^{\circ} \mathrm{C}$ e UR superior a $50 \%$. A decodificação dos dados, segundo o algoritmo elaborado para a caracterização do diâmetro de partículas por difração de raios laser, foi realizada por um programa computacional, e os valores relacionados ao espectro de tamanho de partículas foram processados e tabulados diretamente pelo programa.

Foram avaliadas as seguintes varáveis: gotas menores que $100 \mu \mathrm{m}(\% \mathrm{~V}<100)$, com diâmetro entre 100 e $150 \mu \mathrm{m} \quad(100<\% \mathrm{~V}<150)$, com diâmetro entre 150 e $200 \mu \mathrm{m}$ $(150<\% \mathrm{~V}<200)$, com diâmetro entre 200 e $250 \mu \mathrm{m}(200<\% \mathrm{~V}<250)$, com diâmetro entre 250 e $300 \mu \mathrm{m}(250<\% \mathrm{~V}<300)$, com diâmetro entre 300 e $350 \mu \mathrm{m}(300<\% \mathrm{~V}<350)$, com diâmetro entre 350 e $400 \mu \mathrm{m}(350<\% \mathrm{~V}<400)$,com diâmetro entre 400 e $450 \mu \mathrm{m}(400<\% \mathrm{~V}<450)$, com diâmetro entre 450 e $500 \mu \mathrm{m}(450<\% \mathrm{~V}<500)$, e por gotas maiores que $500 \mu \mathrm{m}(\% \mathrm{~V}>500)$.

Para a análise estatística do espectro de gotas, foi utilizado o delineamento inteiramente casualizado com doze repetições (quatro pontas TT110-01 e três repetições para cada ponta). Os dados foram submetidos ao teste de análise de variâncias (teste F) e, posteriormente, o teste de comparação de médias (Tukey) a 5\% de probabilidade. 


\section{RESULTADOS E DISCUSSÃO}

Conforme tabela 1, as médias das porcentagens dos volumes de gotas pulverizadas com diâmetro menor que $100 \mu \mathrm{m}$ e entre 100 e $150 \mu \mathrm{m}$ diferiram entre si nas diferentes pressões de trabalho em que foram submetidas, sendo que o menor percentual pulverizado foi promovido na pressão de 3 bar (13,42\% de gotas menores do que $100 \mu \mathrm{m}$ e $18,58 \%$ de gotas entre 150 e $200 \mu \mathrm{m}$ ). Conforme houve o aumento da pressão para 5 bar a porcentagem do volume pulverizado de gotas menores que $100 \mu \mathrm{m}$ e entre 150 e $200 \mu \mathrm{m}$ aumentou, isso significa principalmente que houve influência da pressão no espectro de gotas pulverizadas pela ponta (TT-11001). Na porcentagem de volume de gotas pulverizadas entre 150 e $200 \mu \mathrm{m}$ nas três pressões, 3, 4, 5 bares, não houve diferença estatística significativa.

Tabela 1: Porcentagem do volume pulverizado composto por gotas com diferentes diâmetros para a ponta TT-11001, em diferentes pressões.

\begin{tabular}{ccccc}
\hline \multirow{2}{*}{ Ponta } & $\begin{array}{c}\text { Pressão } \\
\text { (Bar) }\end{array}$ & $\mathbf{1 0 0} \boldsymbol{\mu m}$ & $\mathbf{1 5 0} \boldsymbol{\mu m}$ & $\mathbf{2 0 0} \boldsymbol{\mu m}$ \\
\hline \multirow{2}{*}{ TT-11001 } & 3 & $13,42 \mathrm{~A}$ & $18,58 \mathrm{~A}$ & $15,99 \mathrm{~A}$ \\
& 4 & $19,05 \mathrm{~B}$ & $21,38 \mathrm{~B}$ & $16,20 \mathrm{~A}$ \\
& 5 & $21,56 \mathrm{C}$ & $23,34 \mathrm{C}$ & $16,66 \mathrm{~A}$ \\
\hline CV $(\boldsymbol{\%})$ & & $\mathbf{8 , 5 7}$ & $\mathbf{7 , 3}$ & $\mathbf{6 , 4 8}$ \\
\hline
\end{tabular}

Médias seguidas de mesma letra não diferem significativamente a 5\% de probabilidade pelo teste de Tukey.

O aumento de pressão proporcionou a diminuição do DMV. Segundo a classificação da Associação Americana de Engenharia Agrícola ASAE (2000), onde as gotas são classificadas como extremamente grossas $(>450 \mu \mathrm{m})$, muito grossas $(375 \mu \mathrm{m}-450 \mu \mathrm{m})$, grossas $(250 \mu \mathrm{m}-375 \mu \mathrm{m})$, médias $(175 \mu \mathrm{m}-250 \mu \mathrm{m})$, finas $(100 \mu \mathrm{m}-175 \mu \mathrm{m})$ e muito finas $(<100 \mu \mathrm{m})$; assim a ponta TT-11001 apresenta grande porcentagem de gotas de seu espectro classificadas como finas e muito finas.

$\mathrm{Na}$ figura 1 podem ser observadas as médias das porcentagens do volume pulverizado para os diferentes diâmetros de gotas. Desta forma, a maior parte das gotas pulverizadas pela ponta TT-11001 apresenta diâmetro inferior a $200 \mu \mathrm{m}$. 
Figura 1: Médias das porcentagens do volume pulverizado.

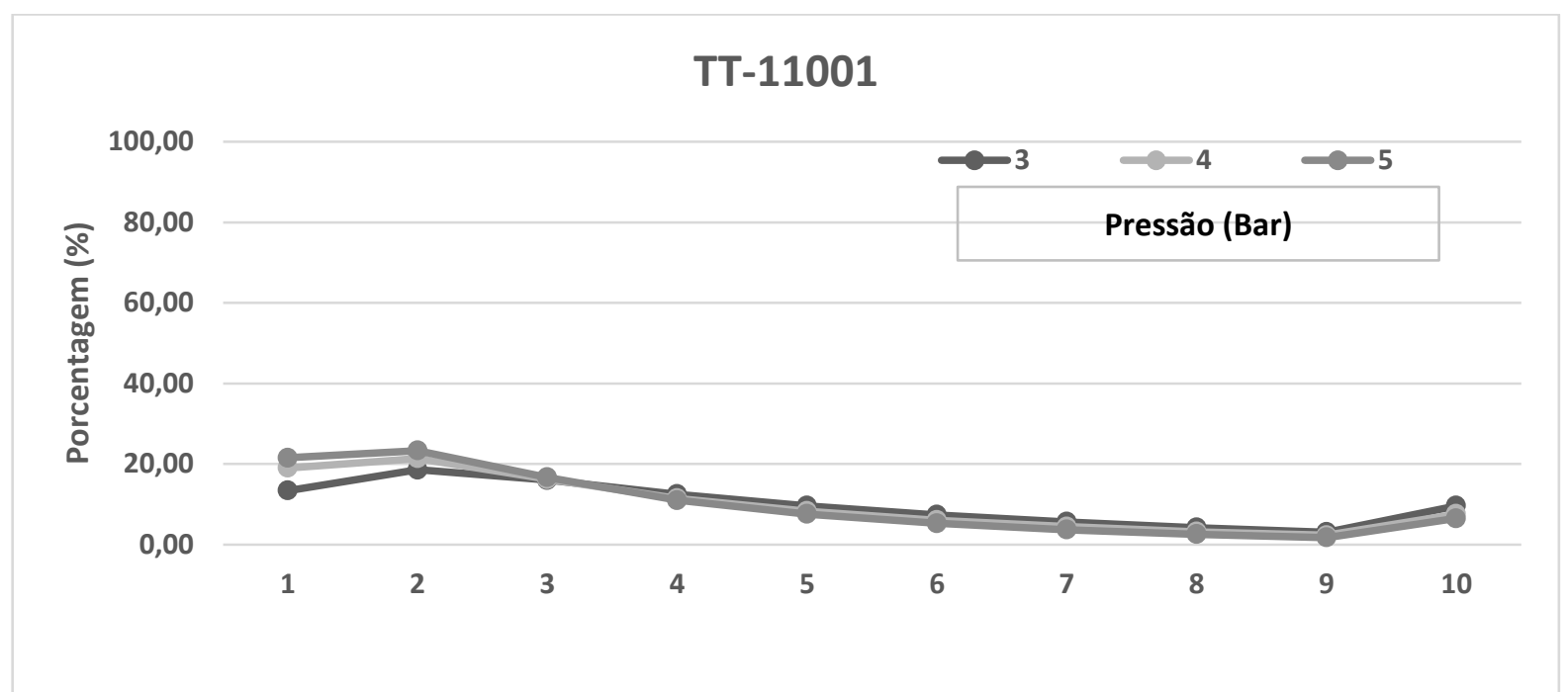

(1) gotas menores que $100 \mu \mathrm{m}(\% \mathrm{~V}<100)$, (2) com diâmetro entre 100 e $150 \mu \mathrm{m}$ $(100<\% \mathrm{~V}<150)$, (3) com diâmetro entre 150 e $200 \mu \mathrm{m}(150<\% \mathrm{~V}<200)$, (4) com diâmetro entre 200 e $250 \mu \mathrm{m}(200<\% \mathrm{~V}<250)$, (5) com diâmetro entre 250 e $300 \mu \mathrm{m}(250<\% \mathrm{~V}<300)$, (6) com diâmetro entre 300 e $350 \mu \mathrm{m}(300<\% \mathrm{~V}<350)$, (7) com diâmetro entre 350 e $400 \mu \mathrm{m}$ $(350<\% \mathrm{~V}<400)$, (8) com diâmetro entre 400 e $450 \mu \mathrm{m}(400<\% \mathrm{~V}<450)$, (9) com diâmetro entre 450 e $500 \mu \mathrm{m}(450<\% \mathrm{~V}<500)$, e $(10)$ por gotas maiores que $500 \mu \mathrm{m}(\% \mathrm{~V}>500)$; para quatro pontas e nas três pressões avaliadas.

Silva et al., (2014) em trabalho avaliando a cobertura de três diferentes pontas de pulverização na cultura da soja, afirmam que pontas que formam gotas de 100-250 $\mu \mathrm{m}$ apresentam maior cobertura do alvo nos diferentes terços das plantas. Por outro lado, médias de DMV inferiores a $250 \mu \mathrm{m}$ indicam potencial risco de deriva, em função das gotas menores que $100 \mu \mathrm{m}$, entretanto, médias de DMV superiores a $500 \mu \mathrm{m}$ indicam problemas de escorrimento que podem ocorrer com gotas maiores que $800 \mu \mathrm{m}$, como observado em estudo de Cunha et al. (2003). Conforme Camara et al. (2018) e de acordo com as recomendações da Teejet technologies (2013), o tamanho das gotas está diretamente ligado a pressão de trabalho dos pulverizadores, ou seja, aumentando-se a pressão, o tamanho das gotas diminui, e aumenta-se o risco de deriva.

Portanto, a ponta TT-11001 pode ser indicada para pulverização em alvos que exigem boa cobertura de calda, porém as condições ambientais devem ser muito favoráveis, evitando risco das gotas se perderem por deriva ou evaporação. 


\section{CONCLUSÕES}

Ao aumentar a pressão de trabalho da ponta TT 110-01, a porcentagem de gotas finas e muito finas aumentou, logo o tamanho das gotas diminuiu. A pulverização de calda com a ponta TT-11001 produz em sua maioria gotas finas e muito finas, nas pressões de 3, 4 e 5 Bar.

\section{REFERÊNCIAS}

AMERICAN SOCIETY OF AGRICULTURAL ENGINEERING -ASAE S572. Spray nozzle classification by droplet spectra. ASAE Standards, St. Joseph, v. 200, p. 389- 391, 2000 .

CAMARA, F. T.; SANTOS, J. L.; SILVA, E. A.; FERREIRA, M. D. C. Volumetricdistributionandspectrumofdropsofhidraulicnozzlesof plane jetofexpanded strip XR11003. Engenharia Agricola, Jaboticabal, v. 28, n. 4, 2008.

CUNHA, J. P. A. R.; BUENO, M. R.; FERREIRA, M. C. Espectro de gotas de pontas de pulverização com adjuvantes de uso agrícola. Planta Daninha, Viçosa, v. 32, p. 1153-1158, 2010. Número Especial.

CUNHA, J. P. A. R.; TEIXEIRA, M. M.; FERNANDES, H. C. Avaliação do espectro de gotas de pontas de pulverização hidráulicas utilizando a técnica da difração do raio laser. Revista Engenharia Agrícola, v.27, n.esp., p.10-15, 2007.

CUNHA, J. P. A. R.; TEIXEIRA, M. M.; COURY, J. R. E.; FERREIRA, L. R. Avaliação de estratégias para redução da deriva de agrotóxico em pulverizações hidráulicas. Planta Daninha, Viçosa, v.21, n.2, p.325-332, 2003.

MATTHEWS, G. A. The application of chemicals for plant disease control. In: WALLER, J.M.; LENNÉ, J.M.; WALLER, S.J. Plant pathologist's pocketbook. London: CAB, 2002. p. 345-353.

MATTHEWS, G. A. Pesticideapplicationmethods. London: Longman, 1979. 334 p.

PERECIN, D.; PERESSIN, V.A.; MATUO, T.; BRAZ, B.A.; PIO, L.C. - Padrões de distribuição de líquidos obtidos com bicos TF-VS4, TJ60-11006 e TQ 15006 em mesa de prova. Pesquisa Agropecuária Brasileira, Brasília, v.33, n.2, p. 175-182, 1998.

SILVA, B. M.; RUAS, R. A. A.; SICHOCKI, D.; DEZORDI, L. R.; CAIXETA, L. F. Deposição da calda de pulverização aplicada com pontas de jato plano em diferentes partes da planta de soja (Glycinemax) e milho (Zeamays). Engenharia na agricultura, Viçosa, v. 22, n.1, p. 17-24, 2014.

TEEJET TECHNOLOGIES. Catálogo 51A-PT. p. 164, 2014. Disponível em: < http://teejet.it/media/464368/cat51a_lo-res_portuguese.pdf>. Acesso em: 09 abr. 2018. 
transversal sobre la eficacia de la pulverización hidráulica. 1997. 310p 